\title{
Ocular Injury Caused by the Bombardier Beetle
}

\author{
Jose Ramon Villada a, b, c Maria Inmaculada Panos a, c, d Irene Del Cerro ${ }^{a}$ \\ Jose Manuel Granados ${ }^{c, d}$ \\ ${ }^{a}$ Cornea and Refractive Surgery Unit, Clinica Baviera, Albacete, Spain; ${ }^{b}$ Refractive Surgery \\ Unit, FYEO Medical, Eersel, The Netherlands; CUniversity of Castilla-La Mancha, Albacete, \\ Spain; ${ }^{\mathrm{C}} \mathrm{CHUA}$ University Hospital, Albacete, Spain
}

\section{Keywords}

Bombardier beetle $\cdot$ Corneal ulcers $\cdot$ Ocular trauma

\begin{abstract}
We report a case of ocular injury caused by a bombardier beetle in a young boy. Ocular injuries due to this coleoptera have not previously been reported. An 11-year-old boy experienced an eye injury while trying to place a bombardier beetle inside an anthill. The boy was diagnosed with a second-degree burn on the skin of the upper right eyelid and conjunctival and corneal erosion in the right eye. The condition resolved completely after 2 weeks of appropriate treatment. Education about the dangers of playing with insects is crucial to prevent this type of lesions.
\end{abstract}

\section{Introduction}

Ocular trauma is a key cause for visual loss and may significantly affect children's quality of life. Corneal erosion is the most common ocular injury [1]. Ocular injuries due to insects have rarely been described, especially in Europe. Bombardier beetles belong to the order Coleoptera, the most diverse in the insect world, comprising $>350,000$ species. All bombardier beetles belong to 1 of 2 subfamilies of ground beetles called Brachininae and Paussinae with $>500$ genera combined. These insects live in all kinds of ecosystems and have been found on all continents, except Antarctica. They are the size of a fingernail $(1-2 \mathrm{~cm})$, and many have dark-colored abdomens with reddish legs, heads, and antennae. When they feel threatened, they synthetize and release a rapid burst of foul-smelling, burning-hot liquid from their rear ends. This is possible, thanks to an internal network of reservoirs and chambers. The explosive power of this fluid blast is derived primarily from the mixture of 2 chemical compounds,

\section{Karger ${ }^{\prime \prime}$}


hydroquinone and hydrogen peroxide, which are stored in a reservoir in the insect's abdomen. When threatened, the beetle squeezes fluid from the reservoir to the reaction chamber, where a mixture of enzymes (catalases and peroxidases) triggers the reaction, which takes the form of release of oxygen from hydrogen peroxide and oxidation of hydroquinone to quinones by the freed oxygen [2]. The fluid mixture is ejected at a speed of $6 \mathrm{~m} / \mathrm{s}$ [3] at a temperature of up to $100^{\circ} \mathrm{C}[4,5]$, and up to a distance of $20 \mathrm{~cm}$ [6]. This produces a distinctly audible popping sound, hence the name bombardier [4]. These insects can aim their abdominal discharge in virtually any direction and may even spray various parts of their own body [7]. We report a case of ocular injury due to the defensive reaction of a bombardier beetle.

\section{Case Report}

An 11-year-old boy was seen as an emergency in our clinic, complaining of severe photophobia and right eye pain. He reported having been spat at in his right eye by a beetle when he was holding it between his fingers and trying to place it inside an anthill. He had been seen previously on the same day at the casualty department of the local hospital, where he was diagnosed with corneal erosion and burn affecting the upper and lower eyelids of the right eye and treated with topical antibiotics and steroids.

The patient was healthy, with no allergies and taking no medication. He was treated for purulent conjunctivitis when aged 6 months. Ocular examination was very difficult as he was severely photophobic and in significant pain. His unaided visual acuity was 0.1 in the right eye and 1 in the left eye. Slit-lamp examination of the right eye revealed swollen upper and lower eyelids with localized skin erythema (Fig. 1), marked mixed conjunctival hyperemia, and an erosion affecting the lower half of the cornea (Fig. 2). There was no activity in the anterior chamber. Steroids were stopped and tobramycin ointment $0.3 \%$ (Tobrex Ointment ${ }^{\circledR}$; Novartis Pharmaceutical) maintained ( 3 times a day to the conjunctival sac and to the eyelids).

When seen 3 days later, his unaided visual acuity in the right eye was 0.8 . The corneal epithelium was closed, leaving only mild pooling of fluorescein and a scab in the area of the eyelid burn. Twice daily fluorometholone 0.1 (FML ${ }^{\circledR}$; Allergan Ltd.) eyedrops were added to the treatment.

After 7 days of treatment, his condition had completely resolved. The corneal epithelium was intact, and there was no pooling of fluorescein. Both the upper and the lower eyelids affected by the burning were slightly pigmented (Fig. 3). The patient was discharged with the recommendation to taper the treatment.

\section{Discussion/Conclusion}

Trauma is an important cause of visual loss in children and may have future repercussions. Jolly et al. [1] performed a retrospective review of all cases of ocular emergencies presenting at the dedicated children's eye casualty department of Moorfields Eye Hospital between January and December 2015. Twenty-one per cent of the patients presented eye trauma, with corneal erosions being the most common (24.6\%). A further 10\% experienced chemical injuries. None of the erosions or chemical injuries were reported to be due to insects. Ratnapalan and Das [8] reviewed all the literature on eye burns in children between 1950 and 2008 and identified 3 major causes, namely, physical agents, chemical agents, and biological agents. The biological agents that caused eye burns were millipedes, snake venom, vesicatory insects such as blistering beetles, and sap from Manchineel trees. The blistering beetles in the aforementioned article produce cantharidin, a very toxic agent that produces important skin and eye reactions on contact.

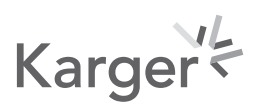


Fig. 1. Swollen upper lid with erythema affecting the skin.
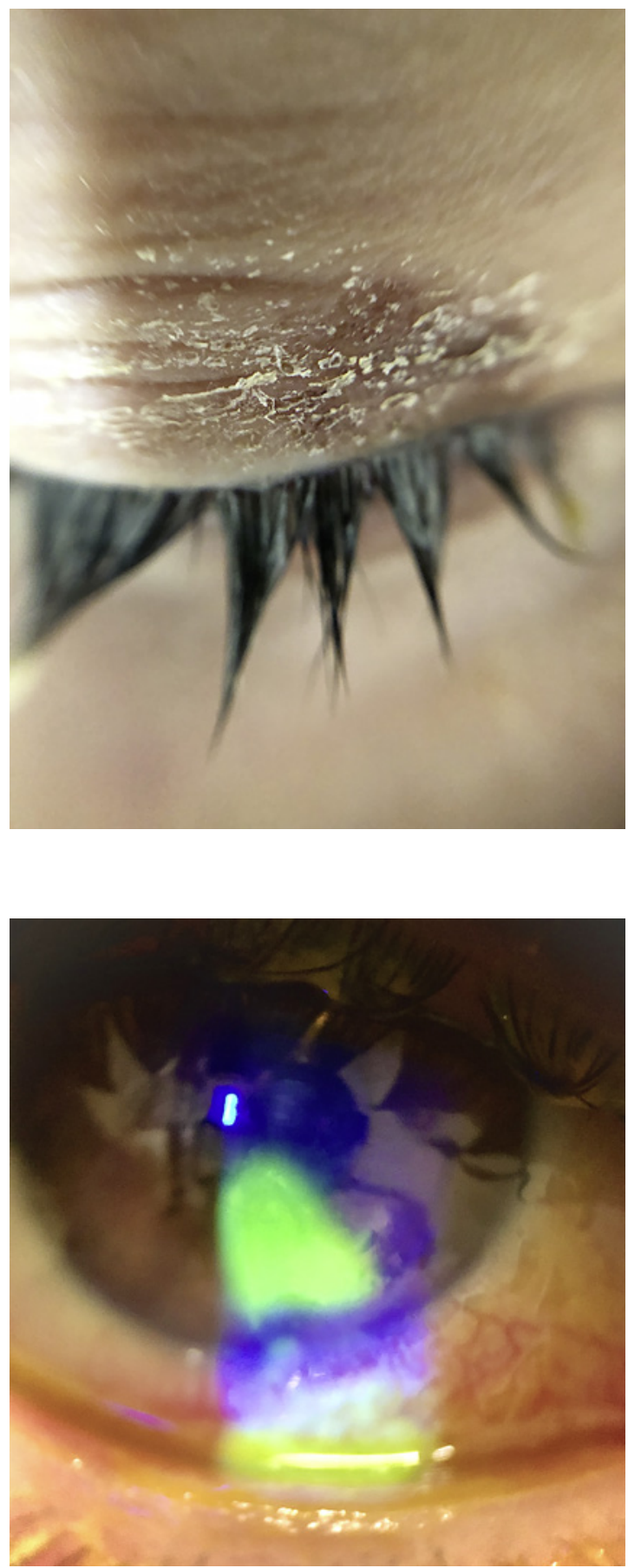

Fig. 2. Erosion of the lower half of the cornea.

Nairobi eye, a condition due to another blistering beetle of the genus Paederus, has been more commonly reported. The Paederus beetle stores pederin, a toxic amide and a potent vesicant in its hemolymph. This beetle does not bite or sting, but accidental brushing or crushing it over the skin leads to the release of pederin, which causes severe contact dermatitis characterized by erythematous and bullous lesions. Contact between a hand with pederin and the eye leads to Nairobi eye, which is characterized by periorbital dermatitis, conjunctivitis, and keratitis. Several authors have reported cases of Paederus dermatitis, with ocular involvement in the form of Nairobi eye in various percentages [9-12]. 
Fig. 3. Residual upper and lower lid lesions.

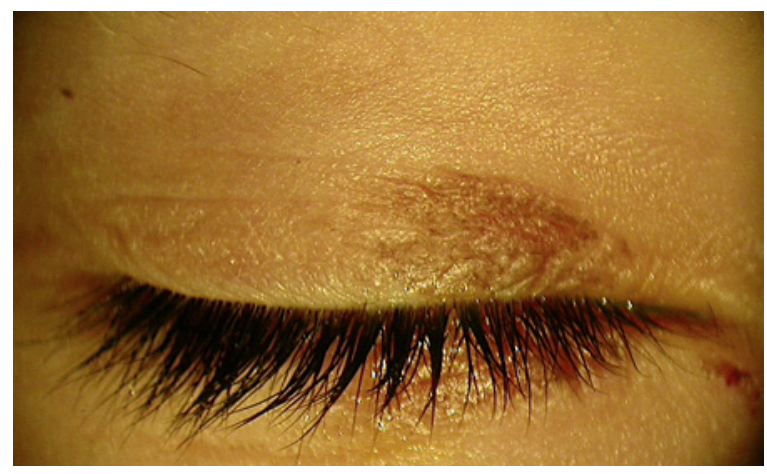

Tiwari et al. [13] described a case of a peripheral ulcerative keratitis after the removal of a corneal foreign body, which seemed to be the shell of an insect; the patient's condition worsened to a total corneal abscess and ended as penetrating keratoplasty.

The case we report differs significantly form the ones discussed before. The insect involved was a bombardier beetle, which has been extensively described in the literature because of its unique defense mechanism. However, it has never been reported to produce ocular injuries, and, to our knowledge, this is the first reported case worldwide of a corneal chemical erosion caused by a bombardier beetle. While the case we report resolved completely, ocular chemical erosions can become complicated and potentially have a less benign resolution. It is important to educate young children to make them aware of possible hazards when playing with insects.

\section{Statement of Ethics}

This case report complies with the guidelines for human, studies and all examinations and retrieval of data were conducted ethically in accordance with the Declaration of Helsinki. Full verbal and written consent were obtained from the patient's parents for publication of this case report and any accompanying images. This study protocol was reviewed and the need for approval was waived by the Ethics Review Committee, University Hospital, Albacete (Spain).

\section{Conflict of Interest Statement}

The authors declare they have no conflict of interest.

\section{Funding Sources}

No funding was received for this research.

\section{Authors Contributions}

Jose R. Villada: examination of the patient, photographs, writing and editing the manuscript, final approval of the version to be published, and agreement to be accountable for all aspects of the work. Maria Inmaculada Panos: examination of the patient, critical review of the manuscript, final approval of the version to be published, and agreement to be accountable 
for all aspects of the work. Irene Del Cerro: examination of the patient, critical review of the manuscript, final approval of the version to be published, and agreement to be accountable for all aspects of the work. Jose Manuel Granados: examination of the patient, photographs, critical review of the manuscript, final approval of the version to be published, and agreement to be accountable for all aspects of the work.

\section{Availability of Data and Material}

All data generated or analyzed in this case report are included in this article and its supplementary material files. Further enquiries can be directed to the corresponding author.

\section{References}

1 Jolly R, Arjunan M, Theodorou M, Dahlmann-Noor AH. Eye injuries in children - incidence and outcomes: an observational study at a dedicated children's eye casualty. Eur J Ophthalmol. 2019;29(5):499-503.

2 Eisner T, Aneshansley DJ, Eisner M, Attygalle AB, Alsop DW, Meinwald J. Spray mechanism of the most primitive bombardier beetle (Metrius contractus). J Exp Biol. 2000;203(8):1265-75.

3 Arndt EM, Moore W, Lee WK, Ortiz C. Mechanistic origins of bombardier beetle (Brachinini) explosion-induced defensive spray pulsation. Science. 2015;348:563-7.

4 Eisner T, Aneshansley DJ. Spray aiming in the bombardier beetle: photographic evidence. Proc Natl Acad Sci U S A. 1999;96(17):9705-9.

5 Eisner T. How the bombardier beetle aims its spray-a tutorial. Am Entomol. 2004;50(2):85-6.

6 McIntosh AC, Lawrence J. The extraordinary design of the bombardier beetle: a classic example of biometrics. In: Whitmore JH, editor. Proceedings of the eight international conference on creationism. Pittsburg, PA: Creation Science Fellowship; 2018. p. 268-76.

7 Sugiura S. Anti-predator defenses of a bombardier beetle: is bombing essential for successful escape from frogs? PeerJ. 2018;6:e5942.

8 Ratnapalan S, Das L. Causes of eye burns in children. Pediatr Emerg Care. 2011;27(2):151-6.

9 Al-Basheer M, Hijazi M, Dama T. Blister beetle dermatosis. a report of 43 cases in a military unit in Eritrea. JRMS. 2002;9(2):40-2.

10 Poole TRG. Blister beetle periorbital dermatitis and keratoconjunctivitis in Tanzania. Eye. 1998;12(5):883-5.

11 Baranwal VK, Goenka R, Gupta RP, Kumar A, Ambiya V. Bugs don't bite to do damage: a study of nairobi eye in the Democratic Republic of Congo. MIMER Med J. 2018;2(2):25-30.

12 Huang FC, Chen WJ, Shih MH. Paederus-induced keratitis. Cornea. 2010;29(8):941-3.

13 Tiwari NN, Kodavoor SK, Ramamurthy D, Ramamurthy S, Ravi J, Faizal M. Peripheral ulcerative keratitis: an extremely rare case presentation after Paederus (beetle) injury. Indian J Ophthalmol. 2019;67(1):120-1. 